\title{
HEALS: A Faith-Based Hypertension Control Program for African-Americans: A Feasibility Study
}

\author{
Sunita Dodani*, Sahel Arora, Dale Kraemer \\ College of Medicine, University of Florida, Jacksonville, USA \\ Email: sunita.dodani@jax.ufl.edu
}

Received 14 July 2014; revised 13 August 2014; accepted 10 September 2014

Copyright (C) 2014 by authors and Scientific Research Publishing Inc.

This work is licensed under the Creative Commons Attribution International License (CC BY).

http://creativecommons.org/licenses/by/4.0/

(c) (i) Open Access

\section{Abstract}

Objective: To determine the feasibility of a behavioral faith-based PREMIER study modified hypertension (HTN) control intervention in a semi urban African-American (AA) church. Methods: In a prospective longitudinal study design, a 12-week behavioral HEALS (Healthy Eating and Living Spiritually) intervention was tested for its feasibility and efficacy in a semi urban AA church. High-risk adult church members with HTN were recruited. Program sessions were weekly delivered by the trained church members. Data were analyzed using repeated measures ANOVA. Results: 22 of 34 subjects ( $65 \%$ retention) provided complete information on the outcome measures. Mean systolic blood pressure (SBP) reduction from baseline was $22 \mathrm{mmHg}(\mathrm{p}<0.001)$ and 6.5 mmHg for diastolic BP $(p=0.0048)$. Mean weight reduction of $3.11 \mathrm{~kg}$ from the baseline $(p<$ 0.0001) was also observed. 91\% subjects attended 7 - 9 sessions. Conclusion: Promoting behavioral HTN control interventions in high risk AAs by empowering AA church communities is feasible and efficacious.

\section{Keywords}

Hypertension, African American, Church-Based, Community-Based Participatory Research, Health Disparity

\section{Introduction}

Despite the declining rates of cardiovascular disease (CVD) related mortalities, geographical and ethnic disparities remain, with higher risk seen in African Americans (AAs). In Florida (FL) particularly, AAs have a higher

\footnotetext{
*Corresponding author.
} 
hypertension (HTN) prevalence (adults AA $41.7 \%$ vs whites $25.4 \%$ ) and suffer more adverse outcomes than whites [1]. AAs develop HTN earlier and have higher average blood pressure (BP) than whites. Additionally, AA women have worse HTN control with lower awareness of HTN [2].

Lifestyle interventions and medications both effectively lower BP [3]. Proven approaches include weight loss, exercise, reduced salt (sodium) intake, improved diet with Dietary Approaches to Stop Hypertension (DASH) style eating pattern, and moderation of alcohol intake [3]. These dietary recommendations also apply to those with pre-HTN and to a large portion of the general population [4]. In the PREMIER trial, DASH with lifestyle modifications was less effective in AAs with regard to BP lowering effects [5]. We believe that "program-effectiveness" studies are required in AA communities, preferably using socio-cultural contexts.

Community based participatory research (CBPR) is an important complement to investigator-led research methods. It has been endorsed by the NIH, CDC, and IOM as a valuable tool to address public health problems. The CBPR model is seen as research "with" the community rather than "on" the community. Our study is designed to build on our existing partnerships with AA churches with a long-term goal to reduce HTN related health disparities. Our intervention, Healthy Eating and Living Spiritually (HEALS), modified from PREMIER (including DASH diets) is a faith-based, socio-culturally modified lifestyle intervention. The objective of this study was to determine 1) the feasibility of implementing HEALS intervention among high-risk AA members of a church and 2) present preliminary data on BP reduction after 12-weeks of intervention.

\section{Methods}

A prospective longitudinal study on high risk AAs with HTN was implemented through an urban AA church in Jacksonville (JAX), FL. The entire study period included several program components that were described in detail elsewhere [1].

\subsection{Establishment of Community Advisory Board (CAB)}

The 14-member CAB was established at the University of Florida, College of Medicine, Jacksonville (UF COM-JAX) to strengthen partnerships between UF COM-JAX and local AA communities and help in planning and implementing HEALS in AA churches. The CAB consist of more than 90\% representation from AA communities including local public/private/government organizations serving low-income ethnic minority groups, leaders from health education institutions, churches, and non-profit organizations. The CAB provided significant input and oversight in the development and implementation of HEALS [6].

\subsection{Development of 12-Weeks Group-Based HEALS Program}

After receiving input on community program needs through focus groups [1], HEALS was developed and modified into a multi-level, culturally-tailored, faith-based group intervention, theoretically grounded in the Social Cognitive Model [7]. Modification in DASH diets were made to a culturally-appropriate diet plan without compromising the integrity of DASH caloric contents. Formed within a spiritual framework, faith-based strategies of the Fit Body and Soul study [8] were used to add faith components. Members of the original DASH and PREMIER teams and CAB members were involved in the modification and development. CAB members selected the spiritual themes and scripture to frame the 3 themes of the intervention-weight loss, increased PA, behavioral change-and wrote messages to be included in the program. The intervention is offered at three levels: Church level (led by pastor), group level (led by trained church members called church health advisors (CHAs)), and individual level (led by CHAs).

\subsection{HEALS Feasibility}

On the recommendation of CAB (based on need), Central Metropolitan Christian Methodist Episcopal (CME) church, located in the semi urban core of JAX, was selected for this study. Training of CHAs was conducted by the HEALS team experts [6]. Key objectives were to familiarize CHAs with the HEALS intervention.

The study was approved by the Institutional Review Board (IRB). CHAs, with the help of HEALS team, recruited eligible members at the church, who included: 1) church members aged 18 - 75 years who provided written informed consent; and 2) known HTN, and/or on HTN medications, or Pre HTN (per JNC-7 classification). All other members were excluded. 
Detailed medical history was obtained on socio-demographics, co-morbidities, drug history and lifestyle habits (e.g. diet, exercise, smoking, alcohol, etc.). 24-hour dietary recalls were used to assess the member's baseline dietary intake and adherence to the programs dietary guidelines [9]. All members were given clear instructions and the study was briefly described.

Weekly sessions were delivered by the CHAs every week for 12 weeks, in the presence of the HEALS team. Sessions were also repeated by the CHAs for members who could not attend. Prior to the start of every session, pastor offered special prayers pertinent to the main theme of every session followed by anthropometric examination that included 1) weight using a calibrated scale; 2) height using a wall-mounted stadiometer; and 3) waist circumference (at the level of $2 \mathrm{~cm}$ above the umbilicus). Body mass index (BMI) was calculated (weight in kilograms/height in meters squared).

An automatic sphygmomanometer (Allen Welch's company) was used with two cuff sizes (normal adult and large). CHAs and research staff took the BP measurements per JNC-7 recommendations. At each session, two BP measurements separated by at least 5 minutes were obtained. Study participants fulfilling BP eligibility criteria had another set of BP measurement on a different day and those who fulfill the criteria both days were included. For each study day and at every assessment point, BP was the mean of two available measurements. Mean BP readings were used for data analysis.

\subsection{Statistical Analysis and Sample Size}

This was a pilot feasibility study to determine, in part, a study completion rate. Thus, this was a convenience sample without a specific sample size target. Descriptive summaries were generated for numeric variables (mean standard deviation, minimum, median, and maximum) and for categorical variable (frequency and proportion). Outcome measures were compared using repeated ANOVA tests.

\section{Results}

A total 34 of 39 of adult church members who provided consent were recruited for the study (Table 1). For the core intervention phase (12 weeks), those who had a $75 \%$ attendance rate were analyzed and termed the "evaluable" group $(\mathrm{n}=22)$. Baseline characteristics were summarized for both evaluable and non-evaluable subjects in Table 1. Overall, 26/34 (77\%) were females; the mean ages were 54.5 years ( \pm 13.86 years) and 53 years $( \pm 12.62)$ in evaluable and non-evaluable groups respectively. Fourteen $(42 \%)$ had at most high school education. The only three smokers were in the non-evaluable group $(\mathrm{p}=0.0368$ compared to the evaluable group).

Within the evaluable group ( $n=22$ ), there were significant changes from baseline to 12-weeks for both SBP and DBP and for weight (Table 2). A mean reduction of $22 \mathrm{mmHg}$ in SBP $(\mathrm{p}<0.001)$ and $6.5 \mathrm{mmHg}$ in DBP $(p=0.0048)$ was seen. A mean weight reduction of $3.11 \mathrm{~kg}$ from the baseline $(\mathrm{p}<0.0001)$ was also observed.

\section{Process Evaluation}

Based on the weekly attendance logs, $68 \%$ of the evaluable participants attended 10 - 12 sessions, $91 \%$ attended 7 - 9 sessions, and $100 \%$ attended at least 6 sessions.

\section{Discussion}

Nationally, the prevalence of HTN is highest among AAs, particularly AA women compared, with to all other racial/ethnic groups of either sex. Additionally, AA women are most disproportionately affected by obesity [10]. It is well established that, despite reducing church memberships in some states, partnerships with churches provide a key opportunity for CBPR programs to underserved populations including AA. Such programs should remain a high priority for public health given that HTN is a major risk factor for CVD. Consistent with this public health priority, HEALS was designed in collaboration with AA communities.

Since the HEALS program has existed in the AA church community, the academic-community partners had already developed a robust partnership by the time the program began in 2013. Challenges tended to be more related to actually implementing the intervention rather than developing or navigating relationships between the institutions and the community partners. First, recruiting members to participate in the study was a challenge. Though this church had more than 400 adult members, however active and regular members were around 150 . 
Table 1. Socio-demographics and other characteristics of adults enrolled in the program $(n=34)$.

\begin{tabular}{|c|c|c|c|}
\hline Characteristics & Evaluable (\%) $n=22$ & Non-evaluable (\%) n = 12 & p-value $(\mathrm{p}<0.05)$ \\
\hline Age: mean $( \pm s d)^{a}$ & $54.5( \pm 13.86)$ & $53( \pm 12.62)$ & 0.599 \\
\hline Gender: n (\%) & & & 0.012 \\
\hline Male & $2(9 \%)$ & $6(50 \%)$ & \\
\hline Female & 20 (91\%) & $6(50 \%)$ & \\
\hline Education n (\%) & & & 0.561 \\
\hline$\geq$ high school & 10 & 4 & \\
\hline Associates degree & 1 & 2 & \\
\hline Bachelor's degree & 6 & 4 & \\
\hline Post-graduate degree & 3 & 2 & \\
\hline Other & 1 & 0 & \\
\hline \multicolumn{4}{|l|}{ Medical conditions: n (\%) } \\
\hline Alcohol consumption & $8(36 \%)$ & $5(42 \%)$ & 1.000 \\
\hline Current Smokers & 0 & $3(25 \%)$ & 0.036 \\
\hline Dyslipidemia & $10(45 \%)$ & $7(58 \%)$ & 0.721 \\
\hline Diabetes mellitus & 7 (32\%) & $4(33 \%)$ & 1.000 \\
\hline Other past medical history & $8(36 \%)$ & 7 (58\%) & 0.288 \\
\hline
\end{tabular}

${ }^{\mathrm{a}} \mathrm{sd}$ - standard deviation

Table 2. Means at baseline, final after 12 weeks, and change from baseline till the end of 12 weeks $(n=22)$.

\begin{tabular}{|c|c|c|c|c|}
\hline & Variable & Mean & Standard deviation & p-value $^{\mathrm{a}}(\mathbf{p}<0.05)$ \\
\hline \multirow{3}{*}{ Baseline } & SBP (mmHg) & 146.7 & 14.88 & \\
\hline & DBP (mmHg) & 82.64 & 10.85 & \\
\hline & Weight (kg) & 86.65 & 17.59 & \\
\hline \multirow{3}{*}{ Final } & SBP (mmHg) & 124.5 & 13.06 & \\
\hline & DBP (mmHg) & 76.14 & 7.56 & \\
\hline & Weight (kg) & 83.54 & 16.30 & \\
\hline \multirow{3}{*}{ Change } & SBP (mmHg) & -22.23 & 16.27 & $<0.0001$ \\
\hline & DBP (mmHg) & -6.50 & 9.67 & 0.0048 \\
\hline & Weight (kg) & -3.11 & 2.81 & $<0.0001$ \\
\hline
\end{tabular}

${ }^{a}$ Wilcoxon's signed rank test

The original recruitment plan was to identify eligible congregation using church bulletin announcements, sending program flyers and invitations from the $\mathrm{CAB}$ and church pastors to church members. We had difficulty getting our information on the church newsletters since the agendas were sometimes made several months in advance.

Second, male church members, particularly smokers, were less interested in participation. While these churches are predominantly attended by females, we made efforts to recruit males but had issues in retaining them. In future studies, efforts should be made to better understand and address barriers in recruiting and retaining male church members in health promotion programs.

Third, the overall retention of study members throughout the 12 weeks program was not ideal. One of the issues was holidays such as Easter, Thanksgiving and Christmas fell in the middle of the program that resulted in poor attendance in sessions. However in our study, nearly $91 \%$ of evaluable study members attended $\geq 8$ of the 12 program sessions that were delivered on every Sunday after church service, and the perceived utility and benefits of the program were substantial. In any event, these church occasions are hard to avoid, therefore careful program planning is required to work around these days. 
In a community-based nutrition/exercise program for AAs, only 33\% adopted and completed the program [11]. Additionally, the proportion of church members (62.5\% retention) who completed the program (evaluable group $n=22$ ) and showed significant changes in BP at the end of the program indicates that the program was efficacious in this group. Retention remains a challenge. One major obstacle was a lack of incentives for CHAs and members for their commitment and valuable time. For future studies, we recommend that every effort should be made to compensate community for their time and commitment, and address common community barriers such as transportation, childcare, etc.

One innovative component of HEALS was the development of the individualized health goals by CHAs for program members. Although conducted as a small scale feasibility study, significant effects were seen for BP reduction and weight loss. In our HEALS study, church members were taught how to prepare healthy menus in the DASH modified eating plan to be socio-culturally tailored and improve physical activity. Subjective reports of increases in fruit and vegetable consumption was identified by many members with improved and healthy servings at the church gatherings. As a result, we achieved greater reduction in both SBP and DBP than PREMIER as well as those observed in the DASH feeding studies, which highlights the potential for translatability and sustainability of our model.

Although feeding studies and carefully controlled clinical trials have shown the positive effect of DASH on BP, DASH data from community-based trials are limited. The translation of DASH into community-based settings has shown that BP decreased participants who attended at least 6 of 8 sessions and adherence to the DASH diet increased when positive messages were associated with dietary goals [12]. In our study, adherence to the HEALS program increased when bible scriptures were reinforced. The percentage of group sessions attended by participants in our study was similar to the percentage attended by study participants in previous communitybased DASH trials, further demonstrating the feasibility of our model [12]. The Body and Soul dietary intervention conducted in AA churches encouraged consumption of 5 servings of fruits and vegetables daily through church-wide nutrition activities, self-help materials, and motivational interviewing [8]. Consistent with socioecological model concepts, the group-mediated format of the Body and Soul sessions promoted modeling, peer support and encouragement, and strategies to promote self-awareness, self-monitoring, and goal setting for healthy eating. Body and Soul demonstrated increased fruit and vegetable consumption by about 1 serving per day relative to a control intervention; however, the Body and Soul intervention did not evaluate BP or HTN. Like Fit Body and Soul diabetes prevention study [8], HEALS also incorporated Body and Soul content in the HEALS modified DASH diets resulting improved fruits and vegetables intake (documented on food log diaries) and greater reduction in BP. Our study did, indeed, show positive changes in and increased confidence for consuming healthy foods in accordance with DASH.

Beside challenges mentioned above, there were other study limitations worth mentioning. The study results are based on a smaller sample due to limited funding that precluded adding a control group with longer term follow-up. Given that this was not a controlled study, we cannot specifically tie our BP reduction changes due to the program, however, it can be argued that the benefits of this type of program do not have to be direct. That is, if involvement in a church based healthy lifestyle HTN control program results in improved HTN control, any route whereby this effect takes place is acceptable. We did not include objective measures of consumption of foods and nutrients associated with DASH, and dietary consumption was based on self-report documented in the participant's food log diaries. The study was not powered to detect significant differences in dietary or anthropometric measures; however, the data provide information about expected effect sizes that will be used for a larger trial.

Despite these limitations, this study provides an example of how community engagement can lead to a CBPR program that not only received high positive ratings from church members, but also provided significant improvements on BP control. Finally, these promising results would seem to provide a strong foundation for conducting a fully-powered randomized trial. Such a trial, as noted above, should allow for more diversity among participants (e.g. sex, smoking status), as well as providing change in outcomes due to HEALs intervention.

\section{Conclusion}

Churches are available in almost every AA community and CBPR programs can access participants who typically do not use traditional health promotion resources. Because AAs have disproportionately greater HTN burden, AAs are a logical target for CVD prevention programs. Research institutions and churches can be dynamic partners to promote health. Communities without access or resources for traditional health promotion programs 
may benefit the most from CBPR programs by empowering the communities. Our study has presented a model of a feasible community/church-based, culturally modified lifestyle program that needs to be evaluated over a longer period in a larger sample.

\section{Acknowledgements}

We would like to acknowledge Rev. Hardrick of Central Metropolitan CME Church, Mrs. Gladys Brown, the CHAs (Delores Young, Lucy James, Jacquelyn Johnson, and Tanisha Ashley), and the members of Central Metropolitan CME Church for their time and dedication to this project. We are indebted to our community advisory board for their consistent input in the program from program modification to implementation. We are thankful to the University of Florida, College of Medicine-Jacksonville for funding this project.

\section{References}

[1] Dodani, S., Arora, S., Lynch, S. and Mahin, C. (2014) HEALS-Faith Based Hypertension Control Program: Focus Group Findings. Health Behavior and Policy Review, 1, 103-110. http://dx.doi.org/10.14485/HBPR.1.2.2

[2] Lewington, S., Clarke, R., Qizilbash, N., Peto, R., Collins, R. and Collaboration, P.S. (2002) Age-Specific Relevance of Usual Blood Pressure to Vascular Mortality: A Meta-Analysis of Individual Data for One Million Adults in 61 Prospective Studies. Lancet, 360, 1903-1913. http://dx.doi.org/10.1016/S0140-6736(02)11911-8

[3] Appel, L.J., Moore, T.J., Obarzanek, E., Vollmer, W.M., Svetkey, L.P., Sacks, F.M., et al. (1997) A Clinical Trial of the Effects of Dietary Patterns on Blood Pressure. DASH Collaborative Research Group. The New England Journal of Medicine, 336, 1117-1124. http://dx.doi.org/10.1056/NEJM199704173361601

[4] Heidenreich, P.A., Trogdon, J.G., Khavjou, O.A., Butler, J., Dracup, K., Ezekowitz, M.D., et al. (2011) Forecasting the Future of Cardiovascular Disease in the United States: A Policy Statement from the American Heart Association. Circulation, 123, 933-944. http://dx.doi.org/10.1161/CIR.0b013e31820a55f5

[5] Appel, L.J., Champagne, C.M., Harsha, D.W., Cooper, L.S., Obarzanek, E., Elmer, P.J., et al. (2003) Effects of Comprehensive Lifestyle Modification on Blood Pressure Control: Main Results of the PREMIER Clinical Trial. The Journal of the American Medical Association, 289, 2083-2093.

[6] Dodani, S., Sullivan, D., Pankey, S. and Champagne, C. (2011) HEALS: A Faith-Based Hypertension Control and Prevention Program for African American Churches: Training of Church Leaders as Program Interventionists. International Journal of Hypertension, 2011, Article ID: 820101.

[7] Bandura, A. (1986) Social Foundations of Thought and Action: A Social Cognitive Theory. Prentice Hall, Upper Saddle River.

[8] Dodani, S. and Fields, J.Z. (2010) Implementation of the Fit Body and Soul, a Church-Based Life Style Program for Diabetes Prevention in High-Risk African Americans: A Feasibility Study. The Diabetes Educator, 36, 465-472. http://dx.doi.org/10.1177/0145721710366756

[9] Carroll, R.J., Midthune, D., Subar, A.F., Shumakovich, M., Freedman, L.S., Thompson, F.E., et al. (2012) Taking Advantage of the Strengths of 2 Different Dietary Assessment Instruments to Improve Intake Estimates for Nutritional Epidemiology. American Journal of Epidemiology, 175, 340-347. http://dx.doi.org/10.1093/aje/kwr317

[10] Chobanian, A.V. (2009) Shattuck Lecture. The Hypertension Paradox-More Uncontrolled Disease Despite Improved Therapy. The New England Journal of Medicine, 361, 878-887. http://dx.doi.org/10.1056/NEJMsa0903829

[11] Lasco, R.A., Curry, R.H., Dickson, V.J., Powers, J., Menes, S. and Merritt, R.K. (1989) Participation Rates, Weight Loss, and Blood Pressure Changes among Obese Women in a Nutrition-Exercise Program. Public Health Reports, 104, 640-646.

[12] Rankins, J., Sampson, W., Brown, B. and Jenkins-Salley, T. (2005) Dietary Approaches to Stop Hypertension (DASH) Intervention Reduces Blood Pressure among Hypertensive African American Patients in a Neighborhood Health Care Center. Journal of Nutrition Education and Behavior, 37, 259-264. http://dx.doi.org/10.1016/S1499-4046(06)60281-9 
Scientific Research Publishing (SCIRP) is one of the largest Open Access journal publishers. It is currently publishing more than 200 open access, online, peer-reviewed journals covering a wide range of academic disciplines. SCIRP serves the worldwide academic communities and contributes to the progress and application of science with its publication.

Other selected journals from SCIRP are listed as below. Submit your manuscript to us via either submit@scirp.org or Online Submission Portal.
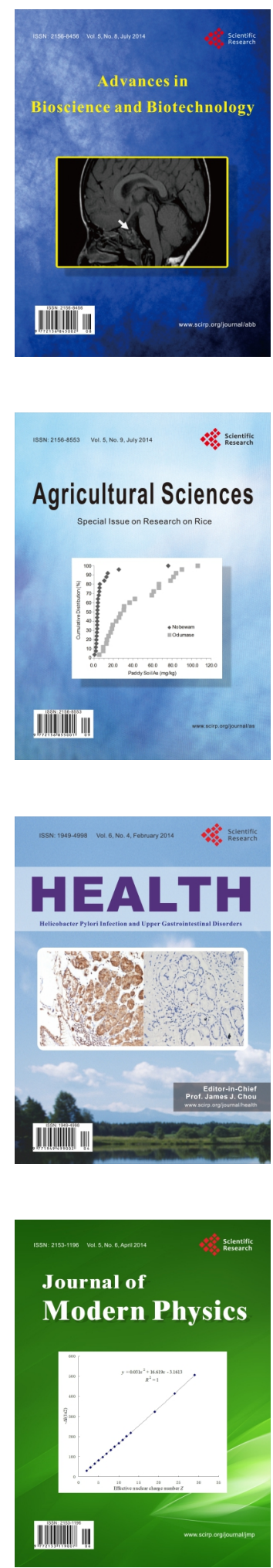
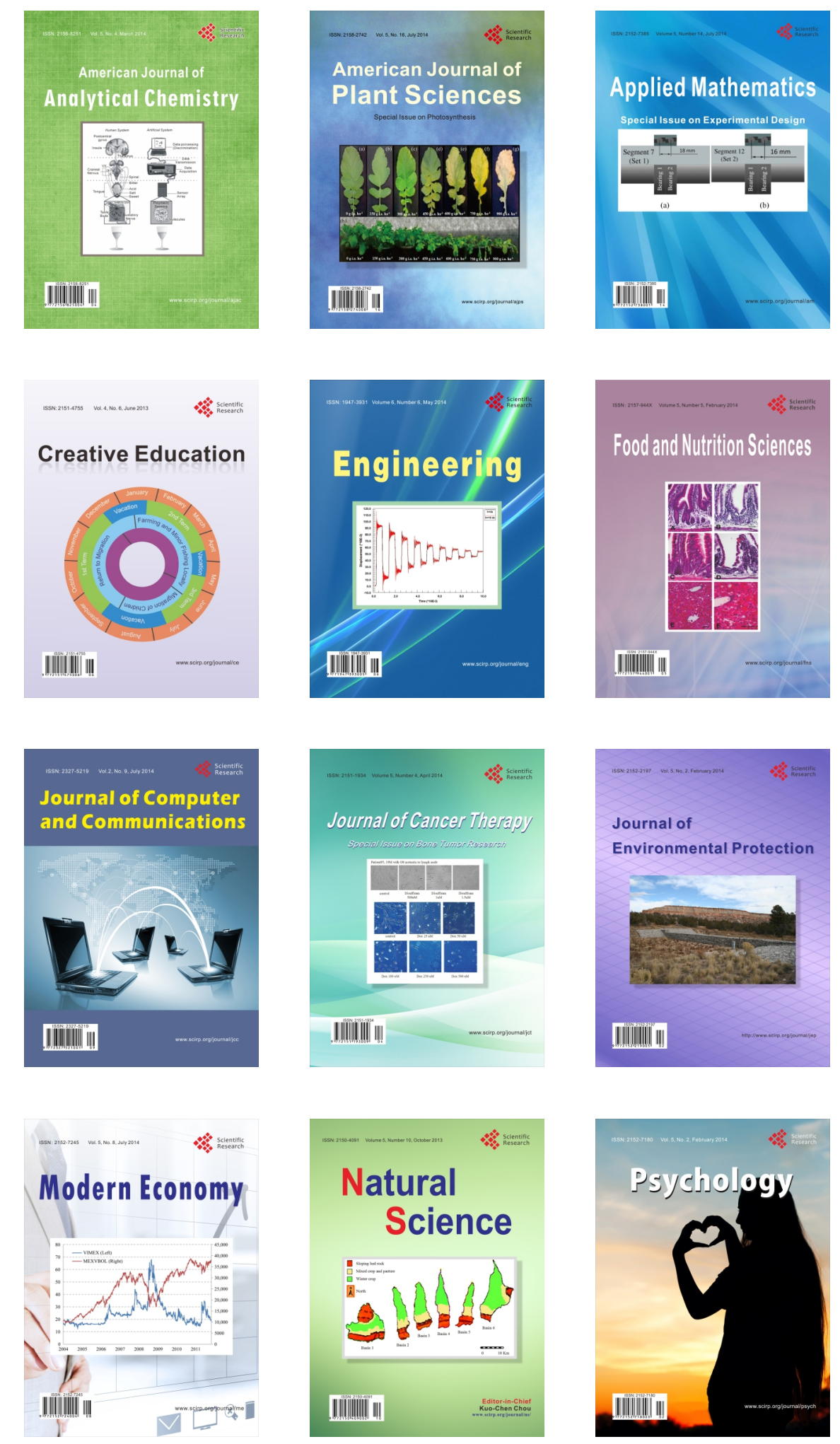